\title{
Orientação sexual: conhecimentos e necessidades de professores de um Colégio Público de Goiânia-Go
}

\author{
Sexual orientation: Knowledges and needs of teachers from a \\ public school from Goiania-GO
}

\section{Orientación sexual: Conocimientyos y necesidades de profesores de un Colegio Nacional de Goiânia-Go}

\author{
Márcia Maria de Souza', Nativa Helena Alves Del-Rios"', \\ Denize Bouttelet Munari"I', Claci Fátima Weirich ${ }^{\prime v}$
}

\section{RESUMO}

A adolescência é marcada por grandes transformações orgânicas, cognitivas, socioculturais e afetivas expondo o adolescente a muitos riscos. Dentre estes, a vulnerabilidade diante das DST como a AIDS é uma realidade. A escola exerce um papel fundamental na formação do aluno, principalmente quanto às informações na esfera da educação sexual e orientação sexual. O estudo tem como objetivo verificar o conhecimento dos professores sobre educação sexual e prevenção de DST, bem como identificar o nível de dificuldade dos mesmos ao lidar com esta temática no ambiente escolar. Trata-se de uma pesquisa descritiva exploratória com abordagem quantitativa, cujos dados foram obtidos através de um questionário semi-estruturado respondido por 28 professores de um colégio público do município de Goiânia/GO. Os resultados demonstram que apesar de considerarem a importância do tema, a maioria dos professores não se sente capacitada para trabalhar a temática educação/orientação sexual com os alunos adolescentes. $61 \%$ dos professores nunca realizaram nenhum trabalho educativo com os alunos no ambiente escolar e somente $39 \%$ já trabalharam utilizando diferentes estratégias. Diante dos resultados obtidos torna-se urgente a implementação de estratégias educativas para a capacitação na temática educação sexual ao grupo de professores.

Palavras chave: Comportamento sexual; Sexualidade; Adolescente; Educação em saúde e Enfermagem em saúde pública.

\section{ABSTRACT}

The adolescence is marked by great organic transformations, cognitives, sociocultural and affectives exposing the adolescent to many risks. Among these, the vulnerability in front of
STD like AIDS is a reality. The school has a fundamental role in the student's formation, mainly about the informations in the sphere of the sexual education an sexual orientation. The study has as objective to check the knowledge of the teachers about sexual education and STD prevention, as well as to identify their level of dificulty to lead with this thematic in school environment. It is one exploratory descriptive research with quantitative approach, whose data were obtained through a semi-structured questionaire answered by 28 teachers from a public school in the city of Goiania/GO. The results show that in spite of considering the importance of the subject, most of teachers don't feel capable to work the thematic sexual education/ orientation with the adolescent students. $61 \%$ of the teachers never realized any educative work with the students in the school environment and only 39\% their yet worked utilizing strategies different. In front of the obtained results, it becomes urgent the implementation of educative strategies to the docents capacitation about the thematic Sexual education.

\footnotetext{
Enfermeira. Doutora em Ciências da Saúde. Professora Adjunto e Pesquisadora do Núcleo de Ações Interdisciplinares em DST/AIDS-NUCLAIDS/FEN/UFG. Faculdade de Enfermagem/UFG. Goiânia/Go. E-mail: marcia@fen.ufg.br

"Acadêmica do Curso de Graduação em Enfermagem da Universidade Federal de Goiás. Bolsista de Iniciação Científica/PIBIC-CNPq. Membro do Núcleo de Ações Interdisciplinares em DST/AIDS-NUCLAIDS/FEN/UFG. Email: nativa_rios@yahoo.com.br

III Enfermeira. Doutora em Enfermagem. Professora Titular da Faculdade de Enfermagem da Universidade Federal de Goiás. Coordenadora do Núcleo de Estudos e Pesquisa em Saúde Integral/FEN/UFG. E-mail: denize@fen.ufg.br

Iv Enfermeira. Doutoranda do Programa de Pós-Graduação em Ciências da Saúde - Convênio UnB/UFG/UFMS. Professora Assistente da FEN/UFG. E-mail: claci@cultura.com.br
} 
Key words: Sexual behavior; Sexuality; Adolescent; Health Education; Public Health Nursing.

\section{RESUMEN}

La adolescencia es marcada por grandes transformaciones orgánicas, cognitivas, socioculturales y afectivas exponiendo al adolescente a muchos riesgos. Dentro de estos, la vulnerabilidad delante de las DST como el SIDA por ejemplo,es una realidad. La escuela ejerce un papel furndamental en la formación del alumno, principalmente en lo que se refiere a las informaciones de la esfera de la educación sexual y orientación sexual. El estudio tiene como objetivo verificar el conocimiento de los profesores al respecto de la educación sexual y prevención de DST, así como identificar el nivel de dificultad de los mismos al trabajar con este tema en el ambiente escolar. Tiene uno pesquisa descriptiva averiguatoria con el siguiente planteo, cantidad, cuyos datos fueron

\section{NTRODUÇÃO}

A fase da adolescência é considerada um período de transição conflituosa entre a infância e a idade adulta, caracterizada por intenso crescimento e desenvolvimento resultando em grandes transformações fisiológicas, anatômicas, psicológicas e sociais. Estas transformações acontecem com todos os jovens dos diferentes continentes e se não forem acompanhados os resultados podem afetar as suas vidas, principalmente sua saúde sexual e reprodutiva, o que pode contribuir para uma gravidez não planejada bem como aquisição de DST e a AIDS(1).

Após o início da epidemia da Aids, as DST readquiriram grande importância como problema de saúde pública mundial. Elas são consideradas facilitadoras para a transmissão sexual dos principais vírus HIV, HBV, HCV e HPV. Sendo que na maioria das vezes a presença de úlceras genitais aumenta o risco de infecção. Logo, controlar a disseminação das DST tornou-se objetivo prioritário do Ministério da Saúde ${ }^{(2)}$.

Os dados epidemiológicos relativos as DST são escassos e irreais pela própria questão da sub-notificação o que torna mais sério ainda a adoção de medidas de prevenção e controle de grande impacto para a diminuição dos índices obtenidos a través de un cuestionario semiestructurado respondido por 28 profesores de un colegio nacional del ayuntamiento de Goiânia/Go. Los resultados demuestran que a pesar de que consideran importante el tema, la mayoría de los profesores no se sienten capacitados para trabajar el tema educación /orientación sexual con los alumnos adolescentes. $61 \%$ de los profesores nunca realizaron un trabajo educativo con los alumnos en el ambiente escolar y sólo $39 \%$ sus todavía trabajamos utilizando el diferente de las estrategias. Delante de los resultados obtenidos se llegó a la conclusión de que lo más rápido posible sean implementadas estrategias educativas para la capacitación de los docentes sobre el tema educación sexual.

Palabras clave: Conducta sexual; Sexualidad; Adolescente; Educación en Salud; Enfermería en Salud Pública.

de contaminação. Porém estima-se que os índices destas infecções são bastante altos em nosso país. Associado a isto, a auto-medicação contribui para aumentar a cadeia de transmissão das doenças, bem como eleva a sua magnitude como problema de saúde pública $^{(2)}$.

As DST podem causar graves complicações à saúde dos jovens quando não diagnosticadas e tratadas a tempo. Durante a gestação, algumas podem ser transmitidas ao feto, causando-lhe lesões irreversíveis, aborto espontâneo, ou mesmo levar a morte fetal ou neonatal. Além da questão psicológica, as DST não deixam de provocar um impacto social que se traduz em custos indiretos para a economia do país ${ }^{(2)}$.

Apesar das suas características epidemiológicas, as DST são consideradas patologias passíveis de intervenção, principalmente, com ações de prevenção primária, incluindo a utilização de métodos contraceptivos como os preservativos masculino e feminino, de forma adequada em todas as relações sexuais. Além disso, todas as DST, exceto aquelas causadas por vírus, possuem tratamento rápido, seguro e eficaz. Portanto, se o portador for conscientizado e informado nas instituições de saúde ou de educação, 
Souza MM, Del-Rios NHA, Munari DB, Weirich CF. Orientação sexual: conhecimentos e necessidades de professores de um Colégio Público de Goiânia-GO. Revista Eletrônica de Enfermagem [Internet]. 2008; 10(2):460-471. Available from: http://www.fen.ufg. br/revista/v10/n2/v10n2a17.htm

certamente a cadeia de transmissão das DST será rompida e, por conseqüência, as infecções causadas pelos vírus com transmissão por via sexual ${ }^{(2)}$

De fato, o controle das DST é possível, desde que existam efetivamente programas de prevenção primária e uma rede de serviços básicos resolutivos ${ }^{(2)}$. A prevenção é considerada pelo Ministério da Saúde uma estratégia básica e de baixo custo para o controle da transmissão das DST e do HIV. Neste sentido, o adolescente torna-se um dos principais alvos, devido à alta vulnerabilidade à aquisição de doenças, principalmente as de transmissão sexual ${ }^{(3)}$.

Nas últimas três décadas, algumas mudanças ocorreram no estilo de vida da população incluindo seus valores, crenças e tabus, principalmente, àqueles relacionados à sexualidade. Hoje os profissionais de saúde e a sociedade em geral estão deixando de controlar a vida sexual dos jovens, transferindo para eles próprios a responsabilidade por sua conduta sexual $^{(4)}$

Essa troca de responsabilidades contribui para a chamada vulnerabilidade institucional e social que inclui a existência de políticas e ações eficazes para o enfrentamento dos problemas relacionados as DST/AIDS. Sabe-se que a desinformação, associada aos estímulos veiculados na mídia e as informações recebidas no seu meio social contribui para a precocidade das atividades sexuais ${ }^{(4-5)}$.

O trabalho de educação em saúde tornase um importante meio de se fazer prevenção ainda mais em se tratando de orientação sexual. Estudos recentes mostram que o ambiente escolar é um espaço apropriado para o desenvolvimento de programas dinâmicos e interativos e de socialização entre educandos e educadores no trabalho desta temática ${ }^{(5-6)}$.

A orientação sexual no ambiente escolar é um dos objetivos do Projeto Nacional Saúde e Prevenção nas Escolas (SPE), lançado em 2004 pelo Governo Federal que conta com as parcerias dos Ministérios da Saúde e Educação, UNESCO e UNICEF. Seu objetivo principal é estimular as escolas de todo país a contemplar em seus projetos pedagógicos a temática "Educação Sexual" de forma transversal. Esta estratégia propõe que os professores contemplem os conteúdos inerentes a essa temática às áreas convencionais de forma que estejam presentes em todas elas, fazendo relações com a atualidade. Este projeto propõe a criação de momentos para discussões com professores e coordenadores e também com pais e/ou responsáveis de modo a integrá-los ao projeto. Nas diretrizes deste projeto consta que as coordenações das instituições providenciem um local específico o chamado "cantinho da prevenção" para receber/atender o aluno adolescente para o trabalho de orientação e informação em saúde na abordagem sobre a temática educação sexual, com a prática também da disponibilização de $\operatorname{preservativos}^{(7)}$.

Com estes objetivos espera-se estimular o ensino sobre a orientação sexual, sobretudo a prevenção, as quais devem estar propostas no projeto pedagógico da escola contempladas na grade curricular. A escola, nesse sentido, é apontada como uma importante instituição com objetivo de proporcionar momentos para trabalhar a informação de forma geral, principalmente, em se tratando da saúde sexual e reprodutiva dos adolescentes. Nesse sentido a prevenção se torna uma importante estratégia para os agravos como a gravidez não planejada e a prevenção das doenças de transmissão sexual, sobretudo na população jovem. Estudos mostram que quanto menor o nível de escolaridade, maior o índice de gravidez entre adolescentes ${ }^{(7-8)}$.

No entanto, a escola apresenta dificuldades em cumprir seu papel social e pedagógico, visto que, para a execução deste trabalho é necessário que todo corpo docente esteja motivado e se sinta capacitado para trabalhar a temática no ambiente escolar.

Frente a tal contexto, este estudo tem como objetivo verificar o conhecimento dos professores sobre a temática orientação sexual, incluindo a sexualidade a prevenção de DST e a saúde sexual e reprodutiva dos alunos, bem como identificar o nível de dificuldade dos mesmos ao lidar com esta temática no ambiente escolar e as estratégias metodológicas que serão necessárias para a realização do trabalho. 


\section{METODOLOGI A}

Trata-se de pesquisa descritiva exploratória com abordagem quantitativa. 0 estudo foi realizado no mês de junho de 2006 no Colégio Estadual Juvenal José Pedroso, localizado na Vila Pedroso, região leste do município de Goiânia/GO. A escolha desta instituição de ensino se deu por sua localização, funcionamento e estrutura, que é considerada a maior instituição de ensino médio da região leste da cidade, recebendo anualmente um grande número de alunos da região e de cidades circunvizinhas.

O colégio conta com 60 (sessenta) professores, 1 (um) diretor e 1 (um) vicediretor. Dos 60 (sessenta) professores 20 (vinte) lecionam também em outros colégios da rede estadual e 06 também trabalham na rede municipal (Município de Goiânia e/ou Senador Canedo).

A amostra foi constituída de 28 professores $(46,7 \%)$ que foram convidados a participar da pesquisa, apresentando-se espontaneamente. Destes 28 professores, 5 $(17,8 \%)$ lecionam no ensino médio, períodos matutino e noturno e também no ensino fundamental no período vespertino no referido colégio. O restante, ou seja, $23(82,2 \%)$ lecionam somente no período matutino do referido colégio e em outras unidades de ensino da rede municipal e ou particular da cidade.

Para a inclusão dos sujeitos na pesquisa alguns critérios foram considerados como estar presente no dia estabelecido para a aplicação do questionário e aceitar o preenchimento do mesmo.

As disciplinas que os professores ministram aulas estão distribuídas por área do conhecimento, dos 28 professores que participaram deste estudo 24 pertencem à área das ciências humanas; três da área das ciências exatas e somente um professor na área das ciências biológicas, sendo este o único da área em toda a escola.

Para a coleta de dados, foi aplicado um questionário, sendo que a primeira parte focalizava os dados pessoais e a segunda parte era destinada aos dados sobre as questões específicas de conhecimento sobre o tema, a atuação dos professores em salas de aula bem como suas dificuldades no que diz respeito à temática orientação sexual no ambiente escolar. O questionário foi respondido conjuntamente pelos professores que se encontravam reunido numa mesma sala de aula do colégio e utilizaram um tempo médio de 20 minutos. Uma vez informado sobre os objetivos da pesquisa, os professores aceitaram participar mediante o preenchimento do Termo de Consentimento Livre e Esclarecido.

Os dados foram analisados e interpretados utilizando-se da estatística descritiva, expressa por meio de gráficos e tabelas para uma melhor visualização e compreensão dos resultados encontrados.

Vale ressaltar que o projeto de pesquisa foi aprovado pelo Comitê de Pesquisa Médica Humana e Animal do Hospital das Clínicas da Universidade Federal de Goiás, atendendo os padrões estabelecidos pela Resolução 196/96 do Conselho Nacional de Saúde, que trata das Normas de Pesquisa Envolvendo Seres Humanos (CEPMHA/HC/UFG-no 037/06).

\section{RESULTADOS E DISCUSSÃO}

A amostra da pesquisa foi constituída por 28 professores, com idade média variando entre 26 e 63 anos. Destes, oito eram do sexo masculino e 20 do sexo feminino. As caracterizações dos sujeitos podem ser mais bem visualizadas na Tabela a seguir: 
Souza MM, Del-Rios NHA, Munari DB, Weirich CF. Orientação sexual: conhecimentos e necessidades de professores de um Colégio Público de Goiânia-GO. Revista Eletrônica de Enfermagem [Internet]. 2008; 10(2):460-471. Available from: http://www.fen.ufg. br/revista/v10/n2/v10n2a17.htm

Tabela 1: Identificação dos professores pesquisados, caracterizando sexo, idade, área de formação, tempo de trabalho no colégio e disciplina que ministra. Goiânia, GO/2006.

\begin{tabular}{|c|c|c|c|c|c|c|c|c|}
\hline \multirow{2}{*}{ Sujeito } & \multicolumn{2}{|c|}{ Sexo } & \multicolumn{3}{|c|}{ I dade } & \multirow{2}{*}{ Área de formação } & \multirow{2}{*}{$\begin{array}{c}\text { Tempo de trabalho } \\
\text { na escola }\end{array}$} & \multirow{2}{*}{ Disciplina que ministra } \\
\hline & $\mathbf{M}$ & $\mathbf{F}$ & $<30$ & 31-50 & $>50$ & & & \\
\hline 1 & & $x$ & & & $x$ & Pedagogia & $6 m^{1}$ & Coordenação pedagógica \\
\hline 2 & & $x$ & & $x$ & & Ciências humanas & $3 a^{\prime \prime}$ & Sociologia \\
\hline 3 & & $x$ & & $x$ & & Geografia & $5 a$ & Geografia \\
\hline 4 & & $x$ & & $x$ & & Letras & $6 a$ & Língua portuguesa \\
\hline 5 & & $x$ & $x$ & & & Ciências biológicas & $5 a$ & Biologia \\
\hline 6 & & $x$ & & $x$ & & Letras & $10 a$ & Língua portuguesa \\
\hline 7 & & $x$ & & $x$ & & Letras & $7 a$ & $\begin{array}{c}\text { Língua portuguesa e língua } \\
\text { inglesa }\end{array}$ \\
\hline 8 & $x$ & & & $x$ & & Matemática & $9 a$ & Matemática \\
\hline 9 & $x$ & & $x$ & & & Física & $9 a$ & Física \\
\hline 10 & & $x$ & $x$ & & & Geografia & $10 \mathrm{~m}$ & Geografia \\
\hline 11 & & $x$ & & $x$ & & Geografia & $10 a$ & Geografia \\
\hline 12 & & $x$ & & $x$ & & Administração & $9 a$ & $\mathrm{~S} / \mathrm{R}^{*}$ \\
\hline 13 & & $x$ & $x$ & & & Ciências Sociais & $3 a$ & Sociologia \\
\hline 14 & & $x$ & & $x$ & & História & $1 a$ & História \\
\hline 15 & $x$ & & & $x$ & & Geografia & $9 a$ & Geografia \\
\hline 16 & & $x$ & $x$ & & & Letras & $2 a$ & Língua portuguesa \\
\hline 17 & & $x$ & & $x$ & & Educação física & $7 a$ & Educação física \\
\hline 18 & & $x$ & & $x$ & & Pedagogia & $4 m$ & Matemática \\
\hline 19 & $x$ & & & $x$ & & Ciências humanas & $7 a$ & Geografia \\
\hline 20 & $x$ & & & $x$ & & Ciências humanas & $7 a$ & Geografia \\
\hline 21 & $x$ & & & $x$ & & Licenciatura & $9 a$ & Língua portuguesa \\
\hline 22 & & $x$ & & $x$ & & Letras & $5 a$ & Língua inglesa \\
\hline 23 & & $x$ & & $x$ & & História & $9 a$ & História \\
\hline 24 & $x$ & & & $x$ & & Geografia & $6 a$ & Geografia \\
\hline 25 & $x$ & & & $x$ & & Educação física & $5 a$ & Educação física \\
\hline 26 & & $x$ & $x$ & & & Agente administrativo & $7 a$ & $S / R$ \\
\hline 27 & & $x$ & & & $x$ & $\mathrm{~S} / \mathrm{R}$ & $1 a$ & Bibliotecária \\
\hline 28 & & $x$ & & $x$ & & Letras & $\mathrm{S} / \mathrm{R}$ & Língua portuguesa \\
\hline
\end{tabular}

Os professores possuem curso superior completo nas diversas áreas do conhecimento científico, ciências humanas, exatas e biológicas, bem como informática e as disciplinas ministradas são compatíveis com a área de formação. Do total de entrevistados apenas dois possuem pós-graduação lato sensu e um está cursando stricto sensu - área da educação.

Em relação à área de formação, houve predomínio no Curso de Letras, seguido de História e Geografia e o tempo em que estes haviam se formado variou de 5 a 18 anos. 0 período de trabalho nesta instituição variou de quatro meses a dez anos.

A oportunidade de trabalhar com um grupo de professores de uma escola pública em Goiânia-GO mostrou que, de modo geral, estes profissionais possuem dificuldades para assumir a responsabilidade de trabalhar a temática educação sexual no ambiente escolar. Foi identificado que 17 professores têm dificuldades em abordar o assunto no ambiente escolar e 26 relataram sentirem despreparados tecnicamente para trabalhar com os alunos. Observa-se através das respostas no questionário ou mesmo em verbalizações que são vários os motivos que os levam a não realizar as atividades com os alunos.

As respostas sinalizam um despreparo técnico com falta de informações recentes sobre a temática, a vergonha ou o tabu também que os impede de falar sobre o tema e ainda a falta de recursos didáticos disponíveis na escola, com os quais acreditam favorecer uma melhor socialização entre os interessados. O estudo de 
Dotta et al $^{(9)}$ mostra o quanto é relevante para os adolescentes o acesso às informações sobre educação sexual de forma natural e quando se trata de crenças e valores por parte dos participantes, somente a informação não é o bastante, havendo uma real necessidade de se trabalhar os mitos e tabus de uma forma saudável, tranqüila e consciente.

Considerando o ambiente escolar como o principal convívio de socialização dos alunos, principalmente adolescentes, o trabalho com a temática educação sexual se torna uma grande estratégia para a prevenção de agravos e problemas relacionados à sexualidade. Por isso o professor se torna referência para os alunos no quesito informação.

Quanto à realização de algum trabalho educativo sobre a temática em sala de aula, $61 \%$ responderam nunca ter realizado e $39 \%$ já realizaram, conforme pode ser observado na Tabela 2.

Tabela 2: Identificação dos professores pesquisados, caracterizando os trabalhos de sensibilização sobre prevenção das DST, com alunos e pais. Goiânia, GO/2006.

\begin{tabular}{|c|c|c|c|c|}
\hline Sujeito & $\begin{array}{c}\text { Atividades de } \\
\text { sensibilização com os } \\
\text { alunos }\end{array}$ & Atividades realizadas & $\begin{array}{c}\text { Atividades de } \\
\text { sensibilização com } \\
\text { os pais }\end{array}$ & $\begin{array}{l}\text { Atividades } \\
\text { realizadas }\end{array}$ \\
\hline 1 & Sim & Palestras & Não & $\mathrm{S} / \mathrm{R}^{*}$ \\
\hline 2 & Sim & Dinâmicas/oficinas & $\operatorname{sim}$ & $\mathrm{S} / \mathrm{R}$ \\
\hline 3 & $\operatorname{Sim}$ & $\begin{array}{l}\text { Discussões em sala de aula } \\
\text { utilizando textos didáticos }\end{array}$ & Não & $S / R$ \\
\hline 4 & Sim & $\begin{array}{l}\text { Debates, pesquisas e } \\
\text { entrevistas }\end{array}$ & Não & $\mathrm{S} / \mathrm{R}$ \\
\hline 5 & Não & $\mathrm{S} / \mathrm{R}$ & Não & $S / R$ \\
\hline 6 & Não & $\mathrm{S} / \mathrm{R}$ & Não & $\mathrm{S} / \mathrm{R}$ \\
\hline 7 & Não & $\mathrm{S} / \mathrm{R}$ & $\mathrm{S} / \mathrm{R}$ & $S / R$ \\
\hline 8 & Não & $\mathrm{S} / \mathrm{R}$ & Não & $\mathrm{S} / \mathrm{R}$ \\
\hline 9 & Não & $\mathrm{S} / \mathrm{R}$ & Não & $S / R$ \\
\hline 10 & Não & $\mathrm{S} / \mathrm{R}$ & Não & $S / R$ \\
\hline 11 & Sim & $\begin{array}{l}\text { Discussões de texto sobre o } \\
\text { tema sexualidade }\end{array}$ & Não & $S / R$ \\
\hline 12 & $\operatorname{sim}$ & Palestras & Não & $S / R$ \\
\hline 13 & $\operatorname{sim}$ & Palestras informativas & Não & $S / R$ \\
\hline 14 & Não & $S / R$ & Não & $S / R$ \\
\hline 15 & $\operatorname{Sim}$ & $\begin{array}{l}\text { Discussões em sala de aula } \\
\text { com os alunos }\end{array}$ & Não & $S / R$ \\
\hline 16 & Sim & $\begin{array}{l}\text { Aulas de biologia (temas } \\
\text { sobre sexualidade) }\end{array}$ & Não & $S / R$ \\
\hline 17 & Não & $S / R$ & Não & $S / R$ \\
\hline 18 & Não & $\mathrm{S} / \mathrm{R}$ & Não & $\mathrm{S} / \mathrm{R}$ \\
\hline 19 & Não & $S / R$ & Não & $S / R$ \\
\hline 20 & Sim & Palestras & Não & $\mathrm{S} / \mathrm{R}$ \\
\hline 21 & $\operatorname{Sim}$ & Discussões coletivas & $\operatorname{Sim}$ & Reuniões \\
\hline 22 & Não & $\mathrm{S} / \mathrm{R}$ & Não & $\mathrm{S} / \mathrm{R}$ \\
\hline 23 & Não & $\mathrm{S} / \mathrm{R}$ & Não & $\mathrm{S} / \mathrm{R}$ \\
\hline 24 & Não & $S / R$ & Não & $S / R$ \\
\hline 25 & Não & $\mathrm{S} / \mathrm{R}$ & $S / R$ & $S / R$ \\
\hline 26 & Não & $\begin{array}{l}\text { S/R } \\
\text { Debates, filmes, trabalhos, }\end{array}$ & Não & $S / R$ \\
\hline 27 & $\operatorname{Sim}$ & $\begin{array}{l}\text { apresentações, textos e } \\
\text { produções textuais }\end{array}$ & $\operatorname{Sim}$ & $\mathrm{S} / \mathrm{R}$ \\
\hline 28 & $\mathrm{~S} / \mathrm{R}$ & $\mathrm{S} / \mathrm{R}$ & $\mathrm{S} / \mathrm{R}$ & $\mathrm{S} / \mathrm{R}$ \\
\hline
\end{tabular}

*S/R-sem resposta

Dentre as atividades de sensibilização realizadas em sala de aula, a utilização de palestras foi citada por $14,3 \%$ dos professores, seguido pelo uso de discussões textuais $(10,7 \%)$, debates $(7,1 \%)$ e discussões com os alunos $(7,1 \%)$. A estratégia de uso de 
dinâmicas/oficinas foi referida por apenas um professor. O trabalho participativo realizado de forma interativa no ambiente escolar é referido por Freire ${ }^{(10)}$ como necessário, pois aproxima o ensino baseado na participação ativa permitindo uma aproximação da teoria com a prática condizente à realidade, além de mostrar o valor da socialização das experiências e saberes para a democratização do conhecimento.

Tendo em vista que educação sexual é de competência da família, os professores foram questionados se já haviam realizado algum trabalho de sensibilização sobre orientação sexual com os pais dos alunos, ao que a maioria respondeu não terem desenvolvido nenhum trabalho $(78,6 \%)$ (Tabela 2). Essa dificuldade em se trabalhar com os pais dos alunos é apontada por Souza ${ }^{(11)}$ em seus resultados, pelo desconhecimento dos professores sobre o papel da escola no desenvolvimento da orientação sexual, bem como a não distinção entre orientação sexual, educação sexual e ainda o papel da família. Segundo Biscoli et $\mathrm{al}^{(1-2)}$ a escola não pretende substituir o conhecimento que foi transmitido dos pais para os alunos, mas sim complementar estas informações.

Para o sucesso e fortalecimento das discussões sobre educação sexual no ambiente escolar, é necessário que professores e coordenadores promovam atividades/eventos na tentativa de envolver as famílias no diálogo sobre sexualidade, usando o espaço da escola, realizando reuniões de pais, oficinas, mostras científicas e outras ${ }^{(6)}$.

Desta forma os professores foram questionados sobre quais os temas trabalhados com os alunos em sala de aula, cujos resultados estão apresentados na Figura 1.

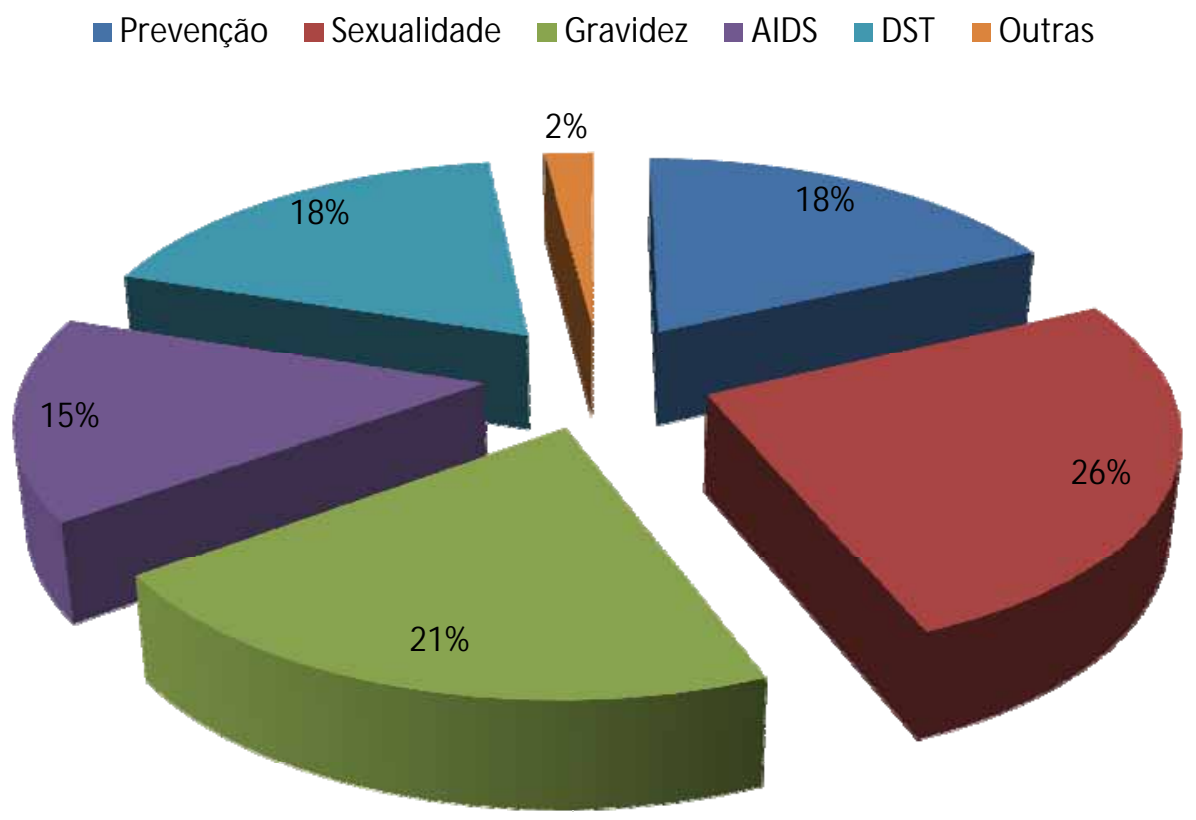

Figura 1: Distribuição de temas vivenciados em salas de aula na instituição estudada. Goiânia/GO, 2006

O fenômeno educacional é compreendido através da dimensão ampliada do conhecimento o qual deve ser abrangente e atual de modo que possa atender $o$ indivíduo na sua complexidade.

O Parâmetro Curricular Nacional- $\mathrm{PCN}^{(13)}$ recomendou a todas as instituições de ensino do país a constar em seus Projetos Político Pedagógicos as temáticas sexualidade, cidadania, ética e meio ambiente. Pensando assim, a temática sexualidade é reconhecida como necessária, mas ainda assunto difícil por muitos educadores da rede de ensino brasileira.

As dificuldades encontradas em se trabalhar a temática sexualidade foram comuns a maioria dos entrevistados, pois além dos tabus e preconceitos ainda arraigados na nossa cultura, ainda falta o preparo técnico com informações atualizadas e recursos didáticos específicos disponíveis na instituição de ensino. 
Souza MM, Del-Rios NHA, Munari DB, Weirich CF. Orientação sexual: conhecimentos e necessidades de professores de um Colégio Público de Goiânia-GO. Revista Eletrônica de Enfermagem [Internet]. 2008; 10(2):460-471. Available from: http://www.fen.ufg. br/revista/v10/n2/v10n2a17.htm

Ao serem questionados sobre a dificuldade em abordar a temática educação sexual em sala de aula a maioria desses profissionais (93\%) respondeu que sentem incapacitados e inseguros para desenvolver este trabalho. Um estudo recente realizado com um grupo de professores de Jandira (SP) mostrou que apenas $33 \%$ deles se sentem seguros em trabalhar a temática sexualidade em sala de aula ${ }^{(5)}$. Os resultados destes dois estudos mostram que apesar de terem sido desenvolvidos em regiões geográficas diferentes no país, a problemática em relação ao preparo do professor é a mesma sendo considerado um problema nacional.

Considera-se que o professor é a peça chave para promover a orientação sexual no ambiente escolar, e por isso há a necessidade emergente de se fazer um trabalho de capacitação tanto no aspecto do conhecimento de conteúdos específicos quanto de uma metodologia adequada para que este possa se sentir cada vez mais capacitado e seguro.

Quanto ao interesse dos alunos pelo assunto, $96,5 \%$ dos professores informaram que os mesmos demonstram interesse pela temática e 3,5\% não demonstram nenhum tipo de interesse. Os conteúdos sobre as temáticas, educação sexual e sexualidade realmente promovem interesse por parte do público jovem, pois os educadores quando vão abordar este assunto tem 0 cuidado de trabalhar atividades educativas com todos os participantes, ou seja, reunidos em grupo o que favorece a participação e a socialização de experiências diversas ${ }^{(14)}$.

A prática de apenas informar parece que não é o suficiente quando se têm em foco a temática educação sexual e especificamente a prevenção das DST/ AIDS entre adolescentes. Hoje não basta apenas que as informações sejam trabalhadas pelo educador ou que só ele fala, pois o adolescente precisa participar neste processo, ele necessita de uma abertura para sua participação, seu potencial deve ser reconhecido e valorizado assim como seus saberes e suas experiências ${ }^{(15)}$. Assim, acreditase que desta forma possa tornar o aprendizado significativo o suficiente para que 0 aluno assuma o compromisso de sua auto responsabilização, zelando pela sua saúde.

Ao serem questionados sobre 0 conhecimento de seus alunos sobre os métodos preventivos de DST e gravidez não planejada, $50 \%$ afirmou que os alunos possuem conhecimento sobre tais assuntos, $42,8 \%$ afirmaram que não possuem e 7,2 \% deles não souberam responder. Quanto a esta questão os professores referiram que seus alunos têm a informação sobre os diversos métodos de prevenção, mas sabem que se a escola disponibilizar materiais educativos para as aulas didáticas como preservativos, masculino $\mathrm{e}$ feminino, próteses, álbuns seriados demonstrativos os alunos se sentiriam mais curiosos e participativos, pois a manipulação desses materiais educativos contribui também para socialização resultando no aprendizado.

Por outro lado, Brêtas e Jardim(5) ao discutirem a esse respeito afirmam que, geralmente a informação veiculada na mídia através de campanhas educativas é muito simplista diante da complexidade do tema sexualidade. De igual forma, os professores colocam no material educativo a expectativa de que estes tornem os adolescentes mais comprometidos com sua saúde sexual.

Ao mesmo tempo, há que se considerar que quanto mais cedo estas questões forem trabalhadas envolvendo os alunos e também a participação dos pais no processo, melhor seriam os resultados, pois haveria a socialização das experiências, com a aproximação dos sujeitos envolvidos e, por conseqüência, a valorização do processo educativo.

Um estudo realizado sobre a experiência sexual dos jovens na faixa etária de 15 a 24 anos, mostra que $49 \%$ fazem uso do preservativo na primeira relação sexual isso apenas nas classes A e B e $57 \%$ nas relações eventuais. Isto revela que a abordagem do sexo seguro entre jovens continua sendo necessária, exigindo esforços para o uso de estratégias criativas que façam sentido nos diferentes contextos sócio-culturais nos quais os jovens experimentam o sexo ${ }^{(16)}$.

Outro estudo(3) ${ }^{(3)}$ realizado em uma escola básica no município de Canoas (RS) revela que, no que tange aos conhecimentos relacionados à 
Souza MM, Del-Rios NHA, Munari DB, Weirich CF. Orientação sexual: conhecimentos e necessidades de professores de um Colégio Público de Goiânia-GO. Revista Eletrônica de Enfermagem [Internet]. 2008; 10(2):460-471. Available from: http://www.fen.ufg. br/revista/v10/n2/v10n2a17.htm

transmissão das DST, esse tema não é totalmente desconhecido dos adolescentes que participaram do estudo. No que se refere ao conhecimento de alunos que já contraíram alguma DST, $78,6 \%$ dos professores desconheciam a problemática, ou seja, não tomaram conhecimento da situação, enquanto $17,8 \%$ souberam que alguns alunos contraíram alguma DST e 3,6\% não souberam responder. Dos $17,8 \%$ que tiveram conhecimento de casos esporádicos, $60 \%$ dos casos infectaram-se pelo Papilomavirus Humano (HPV), ou seja, infecção adquirida através de contato sexual. Este dado é preocupante, pois existe uma grande associação entre alguns grupos de papiloma vírus e o câncer de colo de útero ${ }^{(2)}$. Sabe-se que o HPV é um DNA - vírus não cultivável do grupo papovavírus e que atualmente existem mais de 100 tipos, sendo que 20 podem contaminar o trato genital e alguns destes têm potencial oncogênico maior do que os outros (HPV tipo 16, 18, 45 e 56). Os tipos de alto risco oncogênico, quando associados a outros co-fatores, têm relação com o câncer do colo do útero e vulva e, mais raramente, câncer do pênis e também do ânus ${ }^{(2)}$.

Os professores foram ainda questionados se têm ou já tiveram alunas grávidas, ao que a maioria $(85,7 \%)$ respondeu afirmativamente a questão. Em uma pesquisa realizada em 2004, pela UNESCO os professores pesquisados afirmaram que conhecia mais casos de jovens grávidas no ambiente escolar do que as próprias colegas $^{(1)}$. Isso remete 0 quanto às alunas jovens confiam na pessoa do professor, sendo este profissional considerado o "psicólogo" de muitas alunas, por passarem confiança, permitindo abertura e sigilo para seus problemas ou dificuldades. Essa confiança aumenta pela proximidade e pela socialização das atividades que acontecem diariamente no mesmo ambiente, fortalecendo seus contatos pessoais estreitando relacionamentos.

A gravidez juvenil é uma problemática, esta traz conseqüências drásticas e marcantes para a vida dos jovens, como interrupções de trajetórias esperadas para o prosseguimento normal dos estudos, com vistas à busca de bons empregos, garantindo uma qualidade de vida mais satisfatória além do aspecto da constituição de família(1). Um dos fatores apontados por Ponte Junior e Ximenes Neto ${ }^{(17)}$ que podem levar a gravidez nesta fase da vida é a própria evasão escolar, que devido a ociosidade e falta de projeto de vida predispõe essas adolescentes a aquisição da gravidez.

A presença da escola como promotora da saúde foi evidenciada em um estudo realizado com 28 jovens do Ensino Fundamental de 13 a 16 anos de idade, matriculados em uma escola municipal localizada em um bairro carente da periferia de Fortaleza. Os resultados desse estudo apontam sobre a necessidade de se trabalhar a dialógica freiriana como estratégia de promover educação em saúde no ambiente escolar $^{(18)}$. Esse dado reforça a importância do papel da escola como instituição que contribui para a socialização dos alunos permitindo a troca de saberes, experiências e vivências, o que fortalece as discussões sobre educação sexual por estarem sempre reunidos em grupos, ambiente propício e oportuno para o trabalho com jovens ${ }^{(19)}$.

$\mathrm{Na}$ tentativa de auxiliar os educadores do colégio em implantar o Projeto Nacional "Saúde e Prevenção nas Escolas" no projeto pedagógico escolar, os professores foram questionados quanto aos temas prioritários para a composição do seu programa de qualificação. Os resultados obtidos são apresentados na Tabela 3:

Tabela 3: Distribuição dos temas que os professores apontaram de maior interesse para trabalhar em sala de aula. Goiânia/GO, 2006.

\begin{tabular}{lc}
\hline TEMAS & $\%$ \\
\hline Sexualidade & 35,71 \\
Prevenção das DSTs & 25,85 \\
Gravidez não planejada & 17,75 \\
Métodos contraceptivos & 10,89 \\
Trabalho de conscientização com pais ou responsáveis & 9,80 \\
Total & $\mathbf{1 0 0}$ \\
\hline
\end{tabular}


Apesar da temática sexualidade ser referida pelos entrevistados como a mais vivenciada em sala de aula (Figura 1), eles apontaram interesse em obter informações mais atualizadas, além de estratégias metodológicas a fim de trabalhar a temática com os alunos no ambiente escolar.

Esses resultados reforçam novamente a necessidade de capacitar os professores sobre a temática orientação sexual a ponto de sentirem fortalecidos e com subsídios suficientes para trabalhar a temática no ambiente escolar. Este trabalho deve ser realizado de forma objetiva sem receios e principalmente com segurança, tornando-os agentes multiplicadores da ação educativa fortalecendo a educação em saúde na escola.

\section{CONCLUSÃO}

A realização desse estudo constatou conhecimentos, dificuldades e limitações que o grupo de professores da instituição pesquisada mencionou ao trabalhar a temática sexualidade e, especificamente, a orientação sexual a ser desenvolvida no ambiente escolar.

Após o alcance desse objetivo, verifica-se a necessidade de investimentos em formação de recursos humanos com capacitação específica dessa temática, bem como manter um trabalho de educação permanente com suporte necessário ao processo de continuidade de atividades de educação em saúde no ambiente escolar.

Para a realização deste trabalho é necessário manter uma parceria entre a Universidade e este Colégio, no sentido de realizar atividades conjuntas de ensino, pesquisa e extensão, que acreditamos ampliar o conhecimento do aluno de graduação, bem como beneficiar os alunos da instituição com os trabalhos de educação em saúde.

o conhecimento desse panorama estimulou a participação dos autores dessa pesquisa em um empreendimento mais arrojado junto ao Colégio que conta a partir desse processo com uma parceria entre a Universidade Federal de Goiás (UFG), especificamente a Faculdade de Enfermagem, em atividades de capacitação para seus professores. O intuito desse investimento é o fortalecimento do corpo docente enquanto vigilantes da saúde do escolar, com foco principalmente na saúde sexual e reprodutiva de seus alunos. Assim, essa parceria da Faculdade de Enfermagem da UFG com a instituição reforça a importância do papel do enfermeiro na saúde escolar.

O trabalho do profissional enfermeiro no ambiente escolar, com foco na prevenção por meio da educação em saúde demonstra a importância de se realizar a interação entre escola-família-comunidade-instituições de saúde. Desde a década de oitenta a atuação do enfermeiro no ambiente escolar tem sido decisiva para demonstrar sua capacidade em intervir de forma efetiva na articulação de ações de saúde e educação.

Nesse sentido a parceira da FEN/UFG com a referida escola pode ajudar na implementação de ações que sejam direcionadas para melhorar os conhecimentos dos professores sobre adolescência e sexualidade, já que o presente estudo apontou as fragilidades e limitações destes na educação dos jovens.

Considerando o perfil epidemiológico das doenças sexualmente transmissíveis no panorama mundial e ainda o alto índice de gravidez na adolescência, a adoção de medidas educativas direcionadas a população jovem, na busca de minimizar os riscos que os mesmos estão expostos, é responsabilidade da sociedade como um todo. Assim, o que antes era assunto restrito e função da família tende a ser incorporada também pela escola.

Para tanto, é necessário a busca por instrumentos que capacitem todos aqueles que vão orientar $o$ aluno e não apenas os professores da área de Ciências ou Biologia. Na realidade foi a partir das diretrizes curriculares através do PCN (MEC) que o tema orientação sexual foi incorporado como tema transversal, ou seja, não ser trabalhado somente nas disciplinas da área biológica.

Nesse sentido, defende-se que seja adotada uma postura de "des-biologizar" o tema e entender que este deve ser trabalhado em todas as disciplinas que a grade curricular propõe. A educação sexual deve acontecer de 
maneira eficaz, a partir da compreensão da singularidade e respeito de cada faixa etária, reconhecendo, portanto, que a criança é um ser sexuado e o adolescente desvinculado dos estereótipos que o ligam à liberação dos costumes e a sexualidade com o erotismo associando a questão da promiscuidade. A sexualidade deve ser reconhecida como parte inerente do processo de desenvolvimento da personalidade e não como sinônimo de sexo ou atividade sexual.

Essa concepção parte do princípio também que sexo e sexualidade são essenciais na vida humana, não somente por questões reprodutivas, mas por constituir uma das maiores fontes de prazer humano e realização pessoal.

Diante dos resultados obtidos, percebe-se que há uma real necessidade de intervenção, como a adoção de programas de capacitação pertinentes à realidade dos professores e da escola onde trabalham. Identificou-se durante o processo de execução deste estudo, através de verbalizações, que os próprios professores sentem necessidade de conhecimento específico e aprofundado para o suporte em seus trabalhos junto aos alunos.

Esse fato mostra a importância da garantia e o compromisso por parte dos educadores em trabalhar a temática educação sexual e questões afins que podem surgir no cotidiano escolar. Os estudos ao apontar as principais dificuldades que os professores têm em lidar com a temática educação sexual no ambiente escolar, servem de subsídios e oferece indicadores para os possíveis caminhos que o Colégio precisa seguir para a construção e sustentabilidade do seu projeto político pedagógico.

\section{REFERÊNCI AS}

1. Castro MG, Abramovay M, Silva LB. Juventudes e Sexualidade. Brasília: UNESCO Brasil; 2004.

2. Ministério da Saúde; Secretaria de Vigilância em Saúde, Programa Nacional de DST e AIDS. Manual de bolso das doenças sexualmente transmissíveis (DST). Brasília (Brasil): Ministério da Saúde; 2006.
3. Martini JG, Bandeira AS. Saberes e práticas dos adolescentes na prevenção das doenças sexualmente transmissíveis. Revista Brasileira de Enfermagem. 2003; 56(2): 160-63.

4. Dias A, Bueno SMV. Programa Educativo sobre Sexualidade, DST/AIDS e Sexo Seguro, Desenvolvimento junto aos Alunos do Curso Técnico de Enfermagem: Um relato de Experiência. Revista Nursing. 2003;58(6):1421.

5. Brêtas JRS, Jardim DP. Orientação sexual na escola: a concepção dos professores de JandiraSP. Revista Brasileira de Enfermagem. 2006; 59(2): 157-62.

6. Borges ALV, Nichiata LYI, Schor $N$. Conversando sobre sexo: A rede sociofamiliar como base de promoção da saúde sexual e reprodutiva de adolescentes. Rev. Latino-am Enfermagem. 2006; 14(3): 422-7.

7. Ministério da Educação [Internet]. Brasília: Ministério da Educação (BR) [cited 2007 dez 15]. Projeto Saúde e Prevenção nas Escolas SPE. Available from: http://portal. mec.gov. br/seb/index2.php?option $=$ com_content\&do_pdf=1\&id=685.

8. Brêtas JRS, Silva CV. Interesse de escolares e adolescentes sobre corpo e sexualidade. Revista Brasileira de Enfermagem. 2002; 55(5):528-34.

9. Dotta RM, Alves PB, Koller SH, Brito RC. Sexualidade, Aids e drogas: um relato de intervenção com adolescentes. Rev. Bras. Cresc. Desenv. Hum. 2000; 10(2): 35-44.

10. Freire P. Pedagogia do oprimido. 29ạ edição. São Paulo: Paz e terra; 2000.

11. Souza MM. Construindo a inclusão da temática educação sexual no Projeto Político Pedagógico de um colégio público de GoiâniaGoiás na perspectiva da pesquisa-ação [tese]. [Goiânia]: Programa de Pós-Graduação em Ciências da Saúde - Convênio Rede CentroOeste (UnB/UFG/UFMS); 2007.

12. Biscoli C, Favarão NRLF, Feiten RH, Souza ACP, Perpétuo CL. Sexualidade em Sala de Aula: Um estudo da produção de sentidos. Arq. Ciênc. Saúde UNIPAR [Internet]. 2005 [cited 2007 dez 15];9(1):47-55. Available from: http://revistas.unipar.br/saude/article/viewFile/ 219/193. 
13. Ministério da Educação. Parâmetro Curricular NacionaL: terceiro e quarto ciclos do ensino fundamental. Introdução aos parâmetros curriculares nacionais. Brasília (Brasil): Ministério da Educação; 1998.

14. Souza MM, Borges IK, Medeiros, M, Teles AS, Munari DB. A Abordagem de Adolescentes em Grupos: o Contexto da Educação em Saúde e Prevenção de DST. J. Bras. Doenças Sex. Transm. 2004; 16(2): 18-22.

15. Marques ES, Mendes DA, Tornis NHM, Lopes CLR, Barbosa MA. Conhecimento dos escolares adolescentes sobre doenças sexualmente transmissíveis/AIDS. Rev. Eletr. Enfer 2006 janabr.; 8(1): 58-62.

16. Villela WV, Doreto DT. Sobre a experiência sexual dos jovens. Cad. Saúde Pública [Internet]. 2006 [cited 2007 fev 12];22(11):2467-72. Available from: http://www.scielo.br/pdf/csp/v22n11/21.pdf.

17. Ponte Junior GM, Ximenes Neto FRG. Gravidez na adolescência no município de Santana do Acaraú/CE - Brasil: uma análise das causas e riscos. Revista Eletrônica de Enfermagem [Internet]. 2004 [cited $2008 \mathrm{fev}$ 10];6(1):25-37. Available from: http://www.fen.ufg.br/revista/revista6_ 1/pdf/f3 gravidez.pdf.

18. Beserra EP, Araújo MFM, Barroso MGTB. Promoção da saúde em doenças transmissíveis uma investigação entre adolescentes. Acta paul. Enferm [Internet]. 2006 [cited 2008 jan 24];19(4):402-7. Available from: http://www.scielo.br/pdf/ape/v19n4/v19n4a06. pdf.

19. Ferriani MGC, Gomes R. Saúde escolar: contradições e desafios. Goiânia: AB editora; 1997.

Artigo recebido em 06.06.07

Aprovado para publicação em 30.06.08 